\title{
Review
}

\section{Therapeutic Value of Garlic (Allium sativum): A Review}

\author{
Haben Fesseha, MVSc, DVM'*; Eyob Goa, DVM² \\ 'Department of Veterinary Surgery and Diagnostic Imaging, School of Veterinary Medicine, Wolaita Sodo University, P. O. Box I38, Wolaita Sodo, Ethiopia \\ ${ }^{2}$ College of Veterinary Science, Mekelle University, P. O. Box 2084, Mekelle, Ethiopia
}

\section{"Corresponding author}

Haben Fesseha, MVSc, DVM

Assistant Professor, Department of Veterinary Surgery and Diagnostic Imaging, School of Veterinary Medicine,Wolaita Sodo University, P. O. Box I38, Wolaita Sodo, Ethiopia;Tel. +251910737790; E-mail: tseyon.h@gmail.com

\section{Article information}

Received: November 29th 2019 ; Revised: December 23 $3^{\text {rd }}$, 2019; Accepted: December 31 ${ }^{\text {st }}$, 2019; Published: December 31 2019

\section{Cite this article}

Fesseha H, Goa E. Therapeutic value of garlic (Allium sativum):A Review. Adv Food Technol Nutr Sci Open J. 2019; 5(3): 107-II7. doi: 10.17।40/AFTNSOJ-5-162

\begin{abstract}
Garlic (Allium sativum) is a source of medicine in many ways in human beings in routine life as well as in animals and its leaves, flowers, and cloves have been used in traditional medicine for a long time. Research in recent decades has shown widespread pharmacological and therapeutic effects of $A$. sativum and its organosulfur compounds especially allicin. The most important chemical constituents of this plant are organosulfur compounds such as allicin, diallyl disulphide, S-allylcysteine, and diallyl trisulfide. These chemicals were used for the treatment of inflammation, cancer, blood pressure, atherosclerosis, and hyperlipidemia as praised by several authors. Additionally, extracts of garlic have been used to treat various diseases and have shown anti-viral, anti-bacterial, anti-fungal, anticoagulative and antioxidant effects. However, few adverse effects have been found with garlic are nausea and vomiting when high quantity consumed. To review the therapeutic values of garlic and its importance in human and veterinary practices. Garlic is safe and rich sources of biologically active compounds with low toxicity. Further studies are needed to confirm the safety and quality of the plants to be used by clinicians as therapeutic agents.
\end{abstract}

\section{Keywords}

Allium sativum; Therapeutic values; Antibacterial; Antifungal; Antiviral; Anticancer; Anticoagulative; Antioxidant; Anti-inflammatory.

\section{INTRODUCTION |}

$\mathrm{T}$ raditional medicines occupy a valuable place amongst rural groups of developing countries for the provision of health care inside the absence of an efficient public health care scheme. ${ }^{1}$ The use of traditional treatments is common in sub-Saharan Africa, and visits to traditional healers remain a prime live of care for many people because of preference, affordability, limitation of practitioners and modern hospitals. ${ }^{2}$ Moreover, traditional medicines may be the supply of remedy for lots of health complications. ${ }^{3,4}$

Garlic, Allium sativum is a member of the Alliaceae family, has been widely recognized as a valuable spice and a popular medicine for various diseases and physiological disorders. The word garlic was originated from the Celtic word meaning pungent. Garlic is cultivated practically throughout the world and appears to have originated in central Asia and then spread to China, the Near East, and the Mediterranean region before moving west to Central and Southern Europe, Northern Africa (Egypt) and Mexico. ${ }^{5-7}$ Garlic has played an essential role for over 7,000-years in central
Asia, Africa, Europe, and the Mediterranean region. ${ }^{8}$

Garlic is a bulb growing to $25-70 \mathrm{~cm}$ with hermaphrodite flowers where its leaves and cloves have been used in traditional medicine for a long time. Aged garlic is used to make aged garlic extract (AGE), a popular herbal supplement that has been proven to boost the immune system and possibly prevent cancer and cardiovascular disease. Additionally, as garlic ages, it loses its strong flavor, so there is no need to worry about breath odor. Garlic can be used for culinary and medicinal purposes. The culinary use includes spicy flavor that mellows and sweetens considerably with cooking. While its medicinal uses include treatment of whooping cough, lung disease, stomach complaint and disorder resulting from childbirth, cold, sore eyes, and earache as well as help in the prevention of heart disease. ${ }^{3,9,10}$ A study on Czech revealed that garlic oil especially dehydrated powder could help in reducing the accumulation of cholesterol in the vascular walls of animals..$^{11,12}$

Allicin (diallyl-dithiosulfinate) is the most important component of garlic and generally claimed to be responsible for its numerous beneficial effects including antibacterial, antiviral, anti- 
fungal and antioxidative effect. Nowadays, the alarming growth of the number of antibiotic-resistant bacteria and difficulties in the treatment of infections has initiated a search for new antibacterial compounds and develop new alternative strategies in combating bacterial infections. Medicinal plants such as garlic, with their long history of use in folk medicine for the treatment of infectious diseases, have become a promising new source of antibacterial agents. Besides, they exhibit a direct antimicrobial activity and/or an indirect activity through synergism with antibiotics that increase their effectiveness. ${ }^{13}$ Hence, this review was prepared with the aim of increasing awareness on the medicinal importance of $A$. sativum in human and veterinary medicine

\section{ALLIUM SATIVUM}

\section{Biosynthesis}

Allicin (allyl 2-propenethiosulfinate or diallyl thiosulfinate) is the principal bioactive compound present in aqueous garlic extract or raw garlic homogenate. It is produced from the non-proteinogenic acid alliin (S-allyl cysteine sulfoxide) upon tissue damage in a reaction that is catalyzed by the enzyme alliinase (Figure 1). Alliinase enzyme is activated when garlic is chopped or crushed and acts on alliin (present in raw garlic) to produce allicin. In addition, structurally analogous thiosulfinates are produced in nature by other Allium species. ${ }^{4,14}$

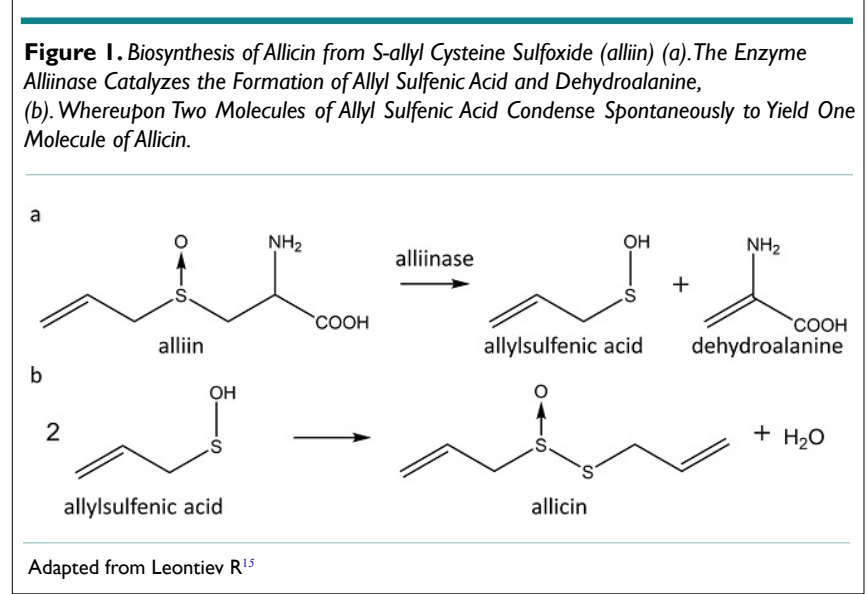

Allyl methyl thiosulfonate, 1-propenyl allyl thiosulfonate, and $\gamma$-L-glutamyl-S-alkyl-L-cysteine are other important sulfur-containing compounds present in garlic. The thiosulfinates are condensation products of two sulfenic acids to form disulfide-S-monoxides and can be viewed as 'sulfenic acid anhydrides. In the laboratory, allicin can be synthesized most effectively by oxidation of diallyl disulfide (DADS) with $\mathrm{H}_{2} \mathrm{O}_{2}$ in the presence of an organic acid catalyst that is first oxidized to the corresponding peroxy-acid, like performic acid or peracetic acid. ${ }^{16}$ The reactivity of thiosulfinates towards thiol-groups is an important component of their antimicrobial activity. The electron-withdrawing effect of the $\mathrm{O}$-atom creates an electrophilic sulfur center which reacts readily with thiols, or more specifically, with thiolate ions (Figure 2), thereby forming an S-allylmercapto adduct. ${ }^{17}$
Figure 2. Reaction Mechanism of a Thiol with a Thiosulfinate. (a). The Reaction Leads Directly, (b) Indirectly, to the Formation of a Mixed Disulfide, which Under Some Conditions may React Further with RSH in a Thiol-disulfide Exchange Reaction to form RSSR and $\mathrm{R}_{l} \mathrm{SH}$.

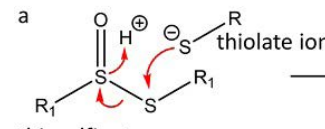

thiosulfinate

b<smiles>[R]SO</smiles>

sulfenic acid

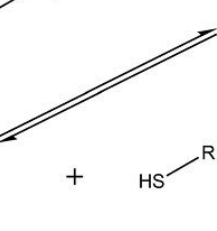

thiol<smiles>[R]SS[R]</smiles>

thial

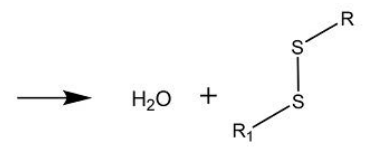

mixed disulfide
Adapted from Leontiev $\mathrm{R}^{15}$

\section{Chemical Constituents of Allium sativum and its Nutritional Value}

A. sativum contains about 33 sulfur compounds, several enzymes, ${ }^{17}$ amino acids, and minerals such as selenium. Studies carried out on the chemical composition of the garlic show that sulfur compounds such as allicin are important constituents of the plant that is responsible for many of its medicinal effects and garlic's pungent odor. Besides, diallyl disulphide (DDS), S-allylcysteine (SAC) and diallyl trisulfide (DTS) are other sulfur compounds that have some roles in the therapeutic effects of the plant. DTS is a chemically stable final transformation product of allicin.,

Garlic powder is a simply dehydrated and crushed garlic clove. Besides, the water extract of heat-treated garlic contains mainly alliin. Accordingly, enzymatic activity of alliinase of garlic powder is similar to that of fresh garlic. However, dehydration temperature should not exceed $60{ }^{\circ} \mathrm{C}$, above which alliinase is inactivated..$^{3,19}$ In contrast to fresh garlic and garlic powder, Garlic oil, and steam-distilled garlic do not have significant amounts of alliin or allicin, but instead, contain various products of allicin transformation. Garlic has been analyzed for moisture, carbohydrate, protein, fat, minerals, vitamins, energy, ash, $\mathrm{pH}$, acidity and essential oil contents. ${ }^{20,21}$ Some of the nutritional and chemical properties of garlic bulbs are summarized in Table 1 .

\begin{tabular}{|c|c|c|c|c|c|}
\hline Properties & Values & Minerals & Values & Vitamins & Values \\
\hline Energy & $119 \mathrm{Kcal}$ & Potassium & $446 \mathrm{mg}$ & Thiamine & $0.16 \mathrm{mg}$ \\
\hline Moisture & $70 \%$ & Phosphorus & $134 \mathrm{mg}$ & Riboflavin & $0.02 \mathrm{mg}$ \\
\hline Protein & $4.3 \mathrm{~g}$ & Magnesium & $24.1 \mathrm{mg}$ & Niacin & $1.02 \mathrm{mg}$ \\
\hline Carbohydrate & $24.3 \mathrm{~g}$ & Sodium & $19 \mathrm{mg}$ & Pyridoxine & $0.32 \mathrm{mg}$ \\
\hline Fiber & $1.2 \mathrm{~g}$ & Calcium & $17.8 \mathrm{mg}$ & Folic acid & $4.8 \mu \mathrm{g}$ \\
\hline Fat & $0.23 \mathrm{~g}$ & Iron & $1.2 \mathrm{mg}$ & Ascorbic acid & $14 \mathrm{mg}$ \\
\hline Alcohol & $0 \mathrm{~g}$ & Zinc & $1.1 \mathrm{mg}$ & Carotenoids & $5 \mu g$ \\
\hline Ash & $2.3 \%$ & lodine & $4.7 \mu \mathrm{g}$ & Vitamin A & Traces \\
\hline $\mathrm{PH}$ & 6.05 & Selenium & $2 \mu g$ & Vitamin E & $0.011 \mu g$ \\
\hline Acidity & $0.172 \%$ & & & & \\
\hline \multicolumn{6}{|c|}{ Source: Pacurar et al ${ }^{22}$} \\
\hline
\end{tabular}




\section{Historical Background and Traditional uses of Allium Sativum}

The ancient Egyptians used garlic to treat diarrhea and its potential medical value was described on the walls of ancient temples and on papyrus dating to 1500 BC. It was used by Greek physicians Hippocrates and Galen to treat intestinal and extra-intestinal diseases; ancient Japanese and Chinese used it to treat headaches, flu, sore throat, and fever. In Africa, particularly in Nigeria, it is used to treat abdominal discomfort, diarrhea, otitis media, and respiratory tract infections. ${ }^{6,8}$

Garlic is nicknamed as Russian penicillin due to its widespread use as a topical and systemic antimicrobial agent; it is commonly used in many cultures as an excitement and reputation of healing power. Garlic was used to treat common colds, hay fever and asthma in Europe and India. ${ }^{23}$ Leaves and cloves of $A$. sativum have been used in traditional medicine of Iran and other countries for a long time. ${ }^{24,25}$ In the pre-antibiotic era, allicin can kill bacteria via the gas phase and was used to successfully treat many lung-pathogenic bacteria such as tuberculosis from crushed garlic preparations through breathing in the vapor. ${ }^{26}$

\section{MEDICINAL IMPORTANCE OF ALLIUM SATIVUM}

Therapeutic use of garlic has been recognized as a potential medicinal value for thousands of years to different microorganisms. Antifungal, antiviral, antibacterial, anthelmintic, antiseptic and anti-inflammatory properties of garlic have been well documented. The extracts exhibited a pronounced activity against both gram-negative (E. coli, Salmonella species, and Citrobacter Enterobacter, Pseudomonas klebsiella) and gram-positive (Staphylococcus aureus, S. pneumonia Group A streptococcus, and Bacillus anthrax) bacteria causing considerable morbidity worldwide. ${ }^{4,6,27}$

\section{Antimicrobial Activity}

Allicin and other sulfur compounds are thought to be the major compounds responsible for the antimicrobial effect of garlic. The antimicrobial properties of garlic were first described by Pasteur in 1958, and since then, many researches had demonstrated its effectiveness and broad-spectrum antimicrobial activity against many species of bacteria, viruses, parasites, protozoan and fungi. ${ }^{26,28}$ Garlic is more effective with the least side effects as compared to commercial antibiotics; as a result, they are used as an alternative remedy for the treatment of various infections. ${ }^{29,30}$ Out of the many medicinal plants, garlic has an antimicrobial property that protects the host from other pathogens highlighting the importance of search for natural antimicrobial drugs. ${ }^{28,31}$ Previously conducted researches confirmed that garlic is not only effective against Gram-positive and Gram-negative bacteria but also possesses antiviral and antifungal activities..$^{26,32,33}$

Anti-bacterial activity: Garlic has been used for centuries in various societies to combat infectious disease. According to different research findings, garlic has been proven to be effective against a plethora of gram-positive, gram-negative, and acid-fast bacteria. These include Salmonella, Escherichia coli. Pseudomonas, Proteus, Staphylococcus aureus, Escherichia coli, Bacillus subtulis, Salmonella spp., Klebsiella spp., Micrococcus spp., Clostridium spp. and Mycobacterium spp. ${ }^{28,31,33,34}$

The gram-positive Staphylococcus aureus was more susceptible to the toxic effects of garlic than its gram-negative counterparts. It has been shown that Gram-negative diarrheagenic pathogens (E. coli, Proteus mirabilis, Shigella spp., and Salmonella spp.,) from stool samples were highly sensitive to garlic. ${ }^{34}$ It has been shown that the aqueous extract of garlic can be used alongside conventional antibiotics to fight agents of nosocomial infections in hospitals. ${ }^{24}$ In vitro and in vivo study of garlic extract was also effective against Streptococcus mutans which is primary etiological organisms in dental caries. ${ }^{5,9,34}$

The cloves of garlic and rhizomes of ginger, extracted with 95\% ethanol, suggested to have antibacterial activity against multi-drug clinical pathogens and can be used for prevention of drug resistant microbial diseases. Pseudomonas aeruginosa was the most sensitive germ to the mixture. Garlic also suggested as a treatment for multi-drug resistant tuberculosis. Besides. allicin in its pure form was found to exhibit antibacterial activity against multidrug-resistant enterotoxicogenic strains of E. coli. ${ }^{33,35}$ In a study by Lai and Roy, fresh extracts of $A$. sativum (garlic) and $N i$ gella sativum (black cumin) had more antibacterial activity against the isolates of the urinary tract infection than cefalexin, cotrimoxazole, and nalidixic acid. Garlic, allyl methyl sulfide, has antibacterial activity against the pig pathogen Actinobacillus pleuropneumoniae serotype $9 ., 24$

Anti-viral activity: Garlic and its sulfur constituents verified antiviral activity against Coxsackievirus species, Herpes simplex virus types 1 and 2, Influenza B, Para-influenza virus type 3, Vaccinia virus, Vesicular stomatitis virus, Human immunodeficiency virus type 1 and Human rhinovirus type 2. The order of compounds found in garlic for virucidal activity was, ajoene $>$ allicin $>$ allyl methyl thiosulfate $>$ methyl allyl thiosulfate; no activity was found for the polar fractions, alliin, deoxy alliin, diallyl disulfide, or diallyl trisulfide. According to different research findings, garlic is an effectual treatment for both the influenza B virus and herpes simplex virus. Two independent researchers in Japan and Romania have found that garlic is able to protect living organisms from the influenza virus and enhanced the production of neutralizing antibodies when given the vaccine. ${ }^{24,36,37}$

Ajoene, isolated from extracts of garlic may inhibit adhesive interaction and fusion of leukocytes. In a study investigating the effect of allitridin (diallyl trisulfide) on the replication of human cytomegalovirus (HCMV) and the expression of viral immediate-early genes, it was revealed that this substance has anti-HCMV efficacy. ${ }^{38}$ In another study, it was supposed that the antiviral activity of garlic in humans may be secondary to a direct toxic effect on viruses. It also enhanced the NK-cell (Natural killer-cell) activity that destroys virus-infected cells. ${ }^{24} \mathrm{On}$, a doubleblind placebo-controlled study has shown significant protection from the common cold virus and used for prevention, treatment and reduction of reinfection benefits from taking allimax powder capsules once daily. ${ }^{4,11,39}$ 
Anti-fungal activity: Different dilutions of extracts of $A$. sativum have been shown to possess fungistatic and fungicidal activity in vitro and in vivo. Ajoene is an active compound found in garlic which plays a great role as a topical antifungal agent. Garlic has been shown to inhibit the growth of fungal diseases as equally as the drug ketoconazole, when tested on the fungi Malassezia furfur, Candida albicans, Aspergillus, Cryptococcus and other Candida species. $^{11,40}$ A report from a Chinese medical journal delineates the use of intravenous garlic to treat a potentially fatal fungal brain infection called Cryptococcus meningitis. Studies on the effect of amphotericin $\mathrm{B}(\mathrm{AmB})$ against Candida. albicans showed that allicin enhances significantly the effect of $\mathrm{AmB}$ against Candida albicans, Saccharomyces cerevisiae and against Aspergillus fumigatus in vitro and in vivo. ${ }^{24,40}$

An in vivo study showed that antibody-alliinase conjugates and alliin are effective against murine pulmonary aspergillosis. ${ }^{41}$ An in vitro study showed both intrinsic antifungal activity of allicin and its synergy with the azoles group of drugs, in the treatment of candidiasis. ${ }^{42}$ One study showed that six different mixtures of garlic distilled oils containing DDS and DTS are active against a number of yeasts (C. albicans, C. tropicalis, and Blastoschizomyces capitatus). ${ }^{30}$ Saponins from $A$. sativum were shown to be effective against Botrytis cinerea and Trichoderma harzianum. ${ }^{43} \mathrm{An}-$ other antifungal protein, allivin, was isolated from $A$. sativum with antifungal activity against Botrytis cinerea, Mycosphaerella arachidicola and Physalospor apiricola. ${ }^{24}$

According to the study made in mice, liquid garlic extract was having a substantial effect in reducing the Candida colonies in mice through stimulating the body's own defenses to enhance the phagocytic activity of the cells. Garlic oil can be used to treat ringworm, skin parasites and warts if it is applied externally. Lesions that were caused by skin fungi in rabbits and guinea pigs were treated with external applications of garlic extract and began to heal after seven days. ${ }^{4,24}$

\section{Anti-Cancer Activity}

Among the most prominent and favorable effects of garlic is its effect on the inhibition of the growth of cancer cells. Diallyl trisulphide (DATS) is one of the components of garlic that has a great effect on fighting cancer cells. The cytotoxicity caused by DATS is mediated by the generation of reactive oxygen species (ROS) and subsequent activation of the ROS-dependent caspase pathway in U937 leukemia cells. The action of garlic has been attributed to stimulating immune effector cells including T-cell and natural killer cells. ${ }^{21,44}$ Numerous epidemiological, clinical and laboratory studies have demonstrated that garlic has a great role in cancer prevention especially in relation to digestive tract cancers. Different studies on humans have shown that regular intake of garlic reduces the risk of esophageal, stomach and colon cancer. This was thought to be due to the antioxidant effect of allicin in reducing the formation of carcinogenic compounds in the gastrointestinal tract..$^{27,45}$

Garlic has also a variety of anti-tumor effects, includ- ing tumor cell growth inhibition and chemopreventive effects. In rodents, garlic and its constituents have been reported to inhibit the development of chemically induced tumors in the liver, colon prostate, bladder, mammary gland, esophagus, lung, skin, and stomach in both rodent and human studies. ${ }^{36,46,47}$ DATS an organosulfur compound isolated from garlic has been shown anticancer activity both in in vitro and in vivo investigations. The cytotoxicity of DATS toward prostate epithelial cells reduced as opposed to PC-3 cancer cells. ${ }^{48}$

The toxic effect of garlic indirectly plays an important role in the death of cancer cells. Another key role in the prevention of cancers is garlic's effect on the immune system. Macrophage activity, NK as well as the cytokine tumor necrosis factor (TNF), were all shown to have increased activity after administration of garlic and this resulted in an increase in antitumor response. ${ }^{4}$ Colorectal cancer is the third leading cause of cancer death in the world. In this respect, normal garlic cannot be administrated and would need to be introduced as part of a strict diet. The garlic and low meat diet, however, show a decrease in colorectal tumor growth. ${ }^{6,11}$

According to different research findings, aged garlic extract such as S-allyl cysteine, and S-allylmercapto-L-cysteine exhibited radical scavenging activity. In addition, S-allyl cysteine and some organosulfur compounds derived from garlic have been found to retard the growth of chemically induced and transplantable tumors in several animal models. Therefore, the consumption of garlic may provide some kind of protection from cancer development. ${ }^{6,24}$

\section{Anti-Helminthic Activity}

Development of anthelmintic resistance in helminths reported in a number of countries gives a clear indication that control programs based exclusively on their use are not sustainable. The development of integrated programs to control helminths is vital, but such control programs require viable alternatives to the use of anthelmintic. ${ }^{49,50}$ Medicinal plants such as garlic have been used to treat parasitic infections in man and animals. A study showed that allicin is able to produce morphological changes in the male Schistosoma mansoni. ${ }^{51}$ The alcoholic extract of bulb of $A$. sativum has also shown moderate in vitro anthelmintic activity against human Ascaris lumbricoldes. Garlic has been reported to be effective in the exposure of dysentery and possess anthelmintic activity against Entamoeba histolytica and Giardia lamblia., ${ }^{4,52}$

Diallyl trisulfide has in vitro activity against several important protozoan parasites. The results indicated that the compound has the potential to be used in the treatment of several human and animal parasitic diseases such as Trypanosoma species, Entamoeba histolytica and Giardia lamblia. ${ }^{11,53,54}$ Garlic oil is effective against a wide range of protozoan parasites including Plasmodium species, Trypanosoma species, Leishmania species, Giardia species, and Cochlospermum planchonii. Its aqueous extract has also been shown to be effective against hymenolepiasis and giardiasis. In an in vitro study, the extracts of $A$. sativum were shown to have anthelmintic 
activity against Haemonchus contortus from sheep by decreasing larval count. The ethanol extract was the most effective in decreasing larval count. In another study, aqueous extract from garlic has good activity against nematodes such as Trichuris muris and Angiostrongylus cantonensis when followed by chloroform extract. ${ }^{6,22,55}$

Garlic with a mixture of the different extracts was tested in vivo and in vitro for its anthelmintic activity against cestodes (Hymenolepis diminuta, H. microstoma, and Taenia taeniaeformis) and trematodes (Fasciola hepatica, Echinostoma caproni). In all in vitro tests, the target parasites died. In addition, the same composition was effective only against Echino. Caproni (intestinal fluke), while both worms were killed in vitro. The essential oil of $A$. sativum has a paralytic effect on F. gigantica. ${ }^{56}$ The extract of $A$. sativum also possesses mosquito larvicidal properties. It is effective against filarial mosquito Culexquinque fasciatus (24-hour post-treatment), Culexquinque fasciatus and Anopheles stephensi. ${ }^{7,57}$ Essential oil from A. sativum has acaricidal activity against Rhipicephalus (Boophilus) Microplus (Canestrini) tick larvae. ${ }^{58}$ A. sativum has also been an insecticidal activity against larvae of Aedesalbopictus (Skuse), Lycoriella ingénue, and Spodoptera litura at 1000 ppm. 59,60

\section{Anti-Inflammatory Activity}

Garlic extracts have been shown to exert anti-inflammatory effects. ${ }^{61}$ In one study, garlic treatment significantly attenuated inflammation and injury of the liver induced by Eimeria papillata infections. ${ }^{53}$ The anti-inflammatory activity exhibited by garlic oil is mainly through inhibiting the assembly-disassembly processes of the cytoskeleton. ${ }^{62}$

Cytokines involved in inflammatory bowel disease (IBD) direct a predominantly cell-mediated T-helper-1 (Th1) immune response. Several compounds isolated from $A$. sativum modulate leukocyte cell proliferation and cytokine production. To investigate the possible therapeutic effects of garlic in the treatment of patients with IBD, whole blood and peripheral blood mononuclear cells (PBMCs) should be assessed. In the presence of various concentrations of garlic extract, in vitro, the effect of garlic extract on leukocyte cytokine production was determined using multiparameter flow cytometry. Accordingly, inflammation associated with IBD can be treated with garlic extract by inhibiting Th1 and inflammatory cytokines while upregulating IL-10 production. An in vivo animal model study needs to be undertaken to determine the significance of these in vitro findings. ${ }^{4,62,63}$

Other authors have shown the preventive effect and possible toxicity of garlic oil and its organosulfur compounds in endotoxin-induced systemic inflammation and intestinal damage. ${ }^{64}$ A lead compound derived from allicin is shown to be a good starting point for the development of anti-inflammatory drugs with fewer side effects. ${ }^{65}$

\section{Anti-Oxidative Activity}

Whole garlic knob and aged garlic extract exhibit direct antioxidant effects and enhance the serum levels of two antioxidant enzymes, catalase, and glutathione peroxidase. ${ }^{18}$ Garlic extract, allicin is efficiently scavenged exogenously generated hydroxyl radicals in a dose-dependent fashion, but their effectiveness was reduced by about $10 \%$ by heating to $100{ }^{\circ} \mathrm{C}$ for $20 \mathrm{~min}$. The sulfur compounds such as S-allyl cysteine, found in fresh garlic appear to be nearly 1000 times more potent as antioxidants than crude, aged garlic extract. Garlic (both the homogenate of 10\% in physiological saline solution and its supernatant) was able to reduce the radicals present in cigarette smoke. ${ }^{66}$

In vivo, antioxidant effects of several garlic organosulfur compounds have been studied. In one study, two lipophilic organosulfur compounds, diallyl sulfide (DAS) and diallyl disulfide (DADS) and two hydrophilic organosulfur compounds, s-ethyl cysteine (SEC) and n-acetylcysteine (NAC), protected against lipid-related oxidations by activating associated antioxidant enzymes. The in vivo antioxidant effects of four test organosulfur compounds against lipid-associated oxidations have been studied by the researcher reported that these antioxidant effects were due to the activation and modification of several enzymes such as 3-hydroxy-3 methylglutaryl-CoA reductase, glutathione-s-transferase and catalase. ${ }^{11,67}$

\section{Anti-Coagulant/Fibrinolytic Activity}

Garlic and other species in the genus allium have played an important role as a prophylactic and therapeutic agent over centuries. Of these, the usefulness of garlic in preventing disease of the cardiovascular system is widely recognized. There are several reports on anticoagulants. ${ }^{68}$ In a study, blood anticoagulant substance was isolated from garlic and its physical and chemical properties were also studied. A half milligram of garlic extracts completely inhibited one millitter of blood from coagulating. The inhibiting effect of garlic extract on blood clotting was almost the same as that of potassium oxalate. , $^{3,41}$

\section{MECHANISMS OF ACTION AND SYNERGISTIC EFFECT OF ALLIUM SATIVUM}

It is widely accepted that plant extracts, because of complex nature, possess multiple mechanisms of action. Garlic extracts and their main components may exhibit activity by: (i) inhibiting bacterial growth or viability, (ii) targeting bacterial virulence factors or (iii) potentiating the effectiveness of antibiotics as resistance modifying agents. The inhibition of bacterial growth occurs through several mechanisms: disruption of membrane function and structure (including the efflux system), interruption of deoxyribonucleic acid/ribonucleic acid (DNA/RNA) synthesis and function, interference with intermediary metabolism and induction of coagulation of cytoplasmic constituents (Table 2). ${ }^{13,69,70}$

Synergistic interaction between two agents, in which one agent enhances the effect of the other and together they act more efficiently than as individual agents. The mechanism of synergistic action is explained by (a) modification of active sites on bacterial cell, (b) inhibition of enzymes, which catalyze degradation or modification of antibiotics, (c) increase of membrane permeabil- 


\begin{tabular}{|c|c|c|c|}
\hline Effect & Pathogen & MOA & Preparation \\
\hline \multirow{8}{*}{ Antibacterial } & Staphylococcus aureus & Inhibition of bacteria growth & $\begin{array}{l}\text { Aqueous, ethanol, chloroform } \\
\text { extract }\end{array}$ \\
\hline & Escherichia coli, Salmonella typhi & $\begin{array}{l}\text { Higher inhibitory effect with Ethanolic extract and } \\
\text { potentiating antibiotics effect }\end{array}$ & Aqueous and ethanolic extract \\
\hline & Bacillus subtilis, Klebsiella pneumonia & Inhibition of bacteria growth with Ethanolic extract & $\begin{array}{l}\text { Aqueous, methanol and ethanol } \\
\text { extract }\end{array}$ \\
\hline & Helicobacter pylori & \multirow{3}{*}{ Higher inhibitory effect } & Extract \\
\hline & Salmonella enteritidis & & Extract \\
\hline & Shigella spp, Proteus mirabilis & & Extract \\
\hline & Actinobacillus pleuropneumonia serotype 9 & \multirow{2}{*}{ Inhibition of bacteria growth } & Extract \\
\hline & Streptococcus mutan & & Extract \\
\hline Antiviral & $\begin{array}{l}\text { Human cytomegalovirus, Influenza B, Herpes simplex virus } \\
\text { type I-2, Parainfluenza virus type } 3 \text {, vaccine virus, Vesicular } \\
\text { stomatitis virus, Human rhinovirus type } 2\end{array}$ & Boost antibody production & Not mentioned \\
\hline \multirow{7}{*}{ Antifungal } & Candidia albicans, C. tropicalis, Blastoschizomyces capitatus & Inhibition by Changing antioxidant metabolites & Extract, DADS \\
\hline & Botrytis cinerea, Trichoderma harzianum & \multirow{3}{*}{ Inhibition of fungal growth } & Extract \\
\hline & Ascosphaera apis & & Essential oil vapors \\
\hline & Paracoccidioides brasiliensis & & Extract \\
\hline & Aspergillus niger & Potentiating antibiotics effect & Extract, Ajoene \\
\hline & Dermatophytes, Saprophytes, Candidia & Blockage of lipid synthesis & Ethanol extract \\
\hline & $\begin{array}{l}\text { Cryptococcal spp., Botr. cinerea, Mycosphaerella arachidicola, } \\
\text { Physalospar apiricola }\end{array}$ & Inhibition of fungal growth & Alcoholic extract \\
\hline \multirow{6}{*}{ Antiparasitic } & Trypanosoma spp, Entamoeba hirtolytica, Giardia lamblia & Inhibition of glutathione reductase & Extract \\
\hline & Schistosoma mansoni & Enhances morphological changes & Extract \\
\hline & Trypanosoma cruzi T. brucei, Plasmodium spp, Giardia spp, & Inhibition of Trypanothione reductase. & Extract \\
\hline & Leishmania spp, Cochlospermum planchomi & Inhibition of glutathione reductase & Extract \\
\hline & Hymenolepiasis, Giardiasis & Muscular paralysis of the parasite & Aqueous extract \\
\hline & Haemonchus contortus & Muscular paralysis of the parasite & $\begin{array}{l}\text { Ethanol, dichloromethane and } \\
\text { water extract }\end{array}$ \\
\hline \multirow{4}{*}{ Other } & Anti-inflammatory effect & $\begin{array}{l}\text { Inhibition of assembly-disassembly processes of the } \\
\text { cytoskeleton }\end{array}$ & Extract \\
\hline & Antioxidant properties & Protection against free radical damage in the body & Organosulfur compound in garlic \\
\hline & Anti-coagulant/ antithrombotic effect & $\begin{array}{l}\text { Suppresses the coagulation system and inhibition of } \\
\text { platelet aggregation }\end{array}$ & Extract \\
\hline & Anti-tumor/cancer & $\begin{array}{l}\text { Enhances immune effector cells, growth inhibition, } \\
\text { and chemopreventive effects }\end{array}$ & Extract \\
\hline Source: Mikaili & & & \\
\hline
\end{tabular}

ity and (d) inhibition of efflux pumps. ${ }^{71}$

Allicin, an antibacterial compound from garlic (A. sativum), potentiated the action of cefazolin (4 to 128-fold) and oxacillin (32 to 64-fold), against Staphylococcus spp. and cefoperazone (8 to 16 -fold) against $P$. aeruginosa. ${ }^{72}$ The significant antibacterial activity of garlic extract on streptomycin-resistant strains (Staph. aureus and E. coli) solely and in synergism with streptomycin has also been proved. ${ }^{73}$ It was found in another study that polymyxin $\mathrm{B}$ (PMB), is effective against various yeasts and filamentous fungi when used in combination with allicin. This combination increases the plasma membrane permeability in Saccharomyces cerevisiae. The synergistic activity between PMB and allicin combinations resulted in the disappearance of the swollen spherical structure of the yeast as a result of structural alterations of its vacuole. ${ }^{74}$ In addition, the synergism between ciprofloxacin and garlic extract has antibacterial activity against multi-drug clinical patho- gens such as enterotoxicogenic strains of E. coli and mycobacterium. ${ }^{29,75}$

\section{DRUG INTERACTION AND PHARMACOKINETICS OF GARLIC}

Glutathione is a compound necessary for the liver to facilitate the detoxification of substances. Organo-sulfur compounds found in garlic showed to prevent glutathione depletion. Patients who experience increases in reactive oxygen-induced stress on liver function may be protected by garlic ingestion. ${ }^{67}$ It was found in $E$. coli cultures that aged garlic extract, S-allyl cysteine, diallyl sulfide, and diallyl disulfide do not interfere with the antibiotic activity of gentamycin but may improve gentamycin-induced nephrotoxicity. ${ }^{23}$ Aged garlic has also been shown to reverse the oxidant effects of nicotine toxicity in rat studies. More researches are required in future garlic may be a unique choice to help minimize 
the toxic effects of therapeutic drugs. ${ }^{3,8}$

One study indicated that those who use traditional/ complementary/alternative medicines (TCAMs) in addition to antiretroviral (ARV) treatment may be at risk of experiencing clinically significant pharmacokinetic interactions, particularly between the traditional complementary alternative medicines and the protease inhibitors as well as non-nucleoside reverse transcriptase inhibitors (NNRTIs). Mechanisms of pharmacokinetic interactions include alterations to the normal functioning of drug efflux transporters, such as P-gp and/or Cytochromes P450 (CYP) isoenzymes, such a CYP3A4 that mediates the absorption and elimination of drugs in the small intestine and liver. Specific mechanisms of action include inhibition and activation of these proteins and induction via the pregnane $\mathrm{X}$ receptor also known as the steroid and xenobiotic sensing nuclear receptor (SXR). Garlic exhibited potentially significant interactions, each with protease inhibitors or non-nucleoside reverse transcriptase inhibitors. ${ }^{24,37}$

In vivo absorption changes are possible between aged garlic extract and cardiovascular, antidiabetic and antiviral drugs, but the magnitude of the changes depends on the most profound process involved (influx, efflux, passive diffusion) in compound's permeability. ${ }^{76}$ In a study, there was some pharmacokinetic interaction of garlic and atorvastatin in dyslipidemic rats was shown. It has been also shown that herbs such as garlic with the potential to significantly modulate the activity of drug-metabolizing enzymes (notably cytochrome P450 isozymes) and/or the drug transporter P-glycoprotein participate in potential pharmacokinetic interactions with anticancer drugs. ${ }^{8,37}$

\section{ADVERSE EFFECT OF GARLIC}

Nausea, vomiting and breath odor are major adverse effects especially when raw forms of the herb are used and care should be taken in consuming high quantities. Although garlic generally poses little in terms of safety issues, there are isolated cases of topical garlic burns and anaphylaxis. ${ }^{67,77}$

According to Tattelman, garlic should be taken with great caution in patients taking anticoagulants. It seems prudent to stop taking high dosages of garlic seven to ten days before surgery because garlic can prolong bleeding time. ${ }^{78}$ One study indicated that garlic application usually results in local inflammation, but, if applied under a pressure bandage, or if there is poor wound care or a secondary infection, it also induces a severe dermal reaction. Data of a study showed that a high garlic dose induced liver toxicity and a pro-oxidative status characterized by increased malondialdehyde and decreased antioxidant enzyme activities as catalase, peroxidase, and superoxide dismutase. Another study suggested that garlic with a high dose has the potential ability to induce liver damage. ${ }^{77,79}$

A parallel study also highlighted the potential ability of a high dose of garlic to induce morphological changes in the liver and kidneys. ${ }^{66}$ Another study also shows intraperitoneal (IP) administration of high doses of garlic $(500 \mathrm{mg} / \mathrm{kg})$ results in profound changes in lung and liver tissues of rats than oral adminis- tration. It is also shown that the adverse effect of high doses of garlic oil might further influence the hemostatic balance. ${ }^{64,68}$

\section{CONCLUSION}

A recent increase in the popularity of alternative medicine and natural products has renewed interest in garlic and their derivatives as potential natural remedies. Garlic, from crushed to capsules, and is consumed throughout the world. Garlic has a lot of benefits and potential uses in preventing and curing different diseases. Fresh and powdered garlic are popular for food flavor and should continue to be used. Nowadays, the problem of bacterial resistance is growing, and the outlook for the use of antibacterial drugs in the future is still uncertain. Even though pharmacological industries have produced a number of new antibiotics in the last few decades, resistance to these drugs by bacteria has increased. Garlic is a valuable source of new and biologically active molecules possessing antibacterial properties through direct action against bacteria or synergism with antibiotics. Garlic's antifungal, antibiotic and perhaps anticancer effects are well-accepted world over because of the many scientific literature supporting these effects. Garlic also has hepatoprotective, antioxidant, and anthelmintic effects as well as unidentified anti-malarial substances. In conclusion, a detailed study regarding the phytochemical assessment and pharmacological effect of garlic and more attention as well as researches regarding the anticoagulant, anti-inflammatory, immunomodulatory and wound-healing action. Besides, advances being made in analytical techniques, sophisticated bioassays, and biotechnological exploitation should provide the means by which these important plants continue to play a key role in the benefit of man and animals' health. Finally, medicinal plants are in danger due to marketing and using them for different activities, so every citizen should give care and conservation in their natural habitat, this can be achieved through public education to increase the awareness of the community about potential uses of medicinal plants.

\section{CONFLICT OF INTEREST |}

The authors declare that they have no conflicts of interest.

\section{REFERENCES}

1. Willcox ML, Bodeker G. Plant-based malaria control: research initiative on traditional antimalarial methods. Parasitol Today. 2000; 16(6): 220-221. doi: 10.1016/s0169-4758(00)01678-1

2. Homsy J, King R, Balaba D, Kabatesi D. Traditional health practitioners are key to scaling up comprehensive care for HIV/ AIDS in sub-Saharan Africa. AIDS. 2004; 18(12): 1723-1725. doi: 10.1097/01.aids.0000131380.30479.16

3. Block E. Garlic Other Alliums: Cambridge, UK: RSC Publishing; 2010.

4. Gebreyohannes G, Gebreyohannes M. Medicinal values of garlic: A review. International Journal of Medicine and Medical Sciences. 2013; 5(9): 401-408. 
5. Houshmand B, Mahjour F, Dianat O. Antibacterial effect of different concentrations of garlic (Allium sativum) extract on dental plaque bacteria. Indian J Dent Res. 2013; 24(1): 71-75. doi: 10.4103/0970-9290.114957

6. Kirha TJ, Thonger T, Kumar S. A Review on the Benefits of Allium sativum on Cancer Prevention. Journal of Cancer Treatment and Research. 2016; 4(5): 34-37. doi: 10.11648/j.jctr.20160405.11

7. Singha S, Chandra G. Mosquito larvicidal activity of some common spices and vegetable waste on Culex quinquefasciatus and Anopheles stephensi. Asian Pac J Trop Med. 2011; 4(4): 288293. doi: 10.1016/S1995-7645(11)60088-6

8. Reddy GD, Reddy AG, Rao G, Kumar MV. Pharmacokinetic interaction of garlic and atorvastatin in dyslipidemic rats. Indian J Pharmacol. 2012; 44(2): 246-252. doi: 10.4103/0253-7613.93860

9. Becker PM, Van Wikselaar PG, Mul MF, et al. Actinobacillus pleuropneumoniae is impaired by the garlic volatile allyl methyl sulfide (AMS) in vitro and in-feed garlic alleviates pleuropneumonia in a pig model. Vet Microbiol. 2012; 154(3-4): 316-324. doi: 10.1016/j.vetmic.2011.07.011

10. Cruz C, Correa-Rotter R, Sánchez-González DJ, et al. Renoprotective and antihypertensive effects of S-allylcysteine in 5/6 nephrectomized rats. Am J Physiol Renal Physiol. 2007; 293(5): F1691-F1698. doi: 10.1152/ajprenal.00235.2007

11. Londhe V, Gavasane AT, Nipate SS, Bandawane DD, Chaudhari PD. Role of garlic (Allium sativum) in various diseases: An overview. Angiogenesis. 2011; 12: 13.

12. Sovova M, Sova P. Pharmaceutical importance of Allium sativum L. 5. Hypolipemic effects in vitro and in vivo. Ceska Slov Farm. 2004; 53(3): 117-123.

13. Stefanović O, Radojević I, Vasić S, Čomić L. Antibacterial Activity of Naturally Occurring Compounds from Selected Plants. London, UK: Intech Open; 2012: 1-25.

14. Fritsch RM, Friesen N. Evolution, Domestication and Taxonomy. Allium Crop Science: Recent Advances. 2002: 5-30. 10.1079/9780851995106.0005

15. Leontiev R, Hohaus N, Jacob C, Gruhlke MC, Slusarenko AJ. A comparison of the antibacterial and antifungal activities of thiosulfinate analogues of allicin. Sci Rep. 2018; 8(1): 6763. doi: 10.1038/s41598-018-25154-9

16. Gruhlke MC, Slusarenko AJ. The biology of reactive sulfur species (RSS). Plant Physiol Biochem. 2012; 59: 98-107. doi: 10.1016/j.plaphy.2012.03.016

17. Albrecht F, Leontiev R, Jacob C, Slusarenko A. An optimized facile procedure to synthesize and purify allicin. Molecules. 2017; 22(5): 770. doi: 10.3390/molecules 22050770
18. Bajpai M, Pande A, Tewari S, Prakash D. Phenolic contents and antioxidant activity of some food and medicinal plants. Int J Food Sci Nutr. 2005; 56(4): 287-291. doi: 10.1080/09637480500146606

19. Ensminger ME, Ensminger AH. Foods \& Nutrition Encyclopedia, Two Volume Set. Florida, USA: CRC Press; 1993.

20. Hacıseferoğulları H, Özcan M, Demir F, Çalışır S. Some nutritional and technological properties of garlic (Allium sativum L.). Journal of Food Engineering. 2005; 68(4): 463-469. doi: 10.1016/j. jfoodeng.2004.06.024

21. Kweon S, Park K-A, Choi H. Chemopreventive effect of garlic powder diet in diethylnitrosamine-induced rat hepatocarcinogenesis. Life Sci. 2003; 73(19): 2515-2526. doi: 10.1016/s00243205(03)00660-x

22. Pacurar M, Krejci G. Garlic Consumption and Health. 2010: 1-60. doi: $10.5772 / 57191$

23. Timbo BB, Ross MP, McCarthy PV, Lin C-TJ. Dietary supplements in a national survey: Prevalence of use and reports of adverse events. J Am Diet Assoc. 2006; 106(12): 1966-1974. doi: 10.1016/j.jada.2006.09.002

24. Mikaili P, Maadirad S, Moloudizargari M, Aghajanshakeri S, Sarahroodi S. Therapeutic uses and pharmacological properties of garlic, shallot, and their biologically active compounds. Iran J Basic Med Sci. 2013; 16(10): 10311048.

25. Statistics F. Major food and agricultural commodities and producers. Web site. http://www fao.org. Accessed November 28, 2019.

26. Jabar MA, Al-Mossawi A. Susceptibility of some multiple resistant bacteria to garlic extract. African Journal of Biotechnology. 2007; 6(6)

27. Kainsa S, Kumar P, Rani P. Medicinal plants of Asian origin having anticancer potential: Short review. Asian J Biomed Pharm Sci. 2012; 2: 1-7.

28. Benkeblia N. Antimicrobial activity of essential oil extracts of various onions (Allium cepa) and garlic (Allium sativum). LWTFood Science and Technology. 2004; 37(2): 263-268. doi: 10.1016/j. lwt.2003.09.001

29. Zain al-abdeen SS, Abdullah IT, Al-Salihi SS. The synergism effect of aqueous garlic extract and ciprofloxacin against some multi-resistant bacteria. J Microbiol Biotech Res. 2013; 3(3).

30. Avato P, Tursi F, Vitali C, Miccolis V, Candido V. Allylsulfide constituents of garlic volatile oil as antimicrobial agents. Phytomedicine. 2000; 7(3): 239-243. doi: 10.1016/s0944-7113(00)80010-0

31. Beuchat LR, Ryu J-H, Adler BB, Harrison MD. Death of Salmonella, Escherichia coli O157: H7, and Listeria monocytogenes 
in shelf-stable, dairy-based, pourable salad dressings. J Food Prot. 2006; 69(4): 801-814. doi: 10.4315/0362-028x-69.4.801

32. Adewumi O, Idowu O. Physicochemical, Microbial load and Sensory properties of milk, yoghurt with or without garlic. Nigerian J Anim Sci. 2014; 16(1): 166-172.

33. Dini C, Fabbri A, Geraci A. The potential role of garlic (Allium sativum) against the multi-drug resistant tuberculosis pandemic: A review. Ann Ist Super Sanita. 2011; 47: 465-473. doi: 10.4415/ANN_11_04_18

34. Eja ME, Asikong BE, Abriba C, Arikpo GE, Anwan EE, Enyi-Idoh KH. A comparative assessment of the antimicrobial effects of garlic (Allium sativum) and antibiotics on diarrheagenic organisms. Southeast Asian J Trop Med Public Health. 2007; 38(2): 343-348.

35. Karuppiah P, Rajaram S. Antibacterial effect of Allium sativum cloves and Zingiber officinale rhizomes against multiple-drug resistant clinical pathogens. Asian Pac J Trop Biomed. 2012; 2(8): 597-601. doi: 10.1016/S2221-1691(12)60104-X

36. Jemal K, Abraham A, Feyissa T. The occurrence and distribution of four viruses on garlic (Allium sativum L.) in Ethiopia. Int J Basic Appl Sci. 2015; 4(1): 5-11.

37. Müller AC, Kanfer I. Potential pharmacokinetic interactions between antiretrovirals and medicinal plants used as complementary and African traditional medicines. Biopharm Drug Dispos. 2011; 32(8): 458-470. doi: 10.1002/bdd.775

38. Zhen H, Fang F, Ye D, et al. Experimental study on the action of allitridin against human cytomegalovirus in vitro: Inhibitory effects on immediate-early genes. Antiviral Res. 2006; 72: 68-74. doi: 10.1016/j.antiviral.2006.03.017

39. Josling P. Preventing the common cold with a garlic supplement: A double-blind, placebo-controlled survey. Adv Ther. 2001; 18(4): 189-193. doi: 10.1007/bf02850113

40. Lemar KM, Aon MA, Cortassa S, O'Rourke B, Müller CT, Lloyd D. Diallyl disulphide depletes glutathione in Candida albicans: oxidative stress-mediated cell death studied by two-photon microscopy. Yeast. 2007; 24(8): 695-706. doi: 10.1002/yea.1503

41. Appel E, Vallon-Eberhard A, Rabinkov A, et al. Therapy of murine pulmonary aspergillosis with antibody-alliinase conjugates and alliin. Antimicrob Agents Chemother. 2010; 54: 898-906. doi: 10.1128/AAC.01267-09

42. Khodavandi A, Alizadeh F, Aala F, Sekawi Z, Chong PP. In vitro investigation of antifungal activity of allicin alone and in combination with azoles against Candida species. Mycopathologia. 2010; 169: 287-295. doi: 10.1007/s11046-009-9251-3

43. Lanzotti V, Barile E, Antignani V, Bonanomi G, Scala F. Antifungal saponins from bulbs of garlic, Allium sativum L. var.
Voghiera. Phytochemistry. 2012; 78: 126-134. doi: 10.1016/j.phytochem.2012.03.009

44. Antony ML, Singh SV. Molecular mechanisms and targets of cancer chemoprevention by garlic-derived bioactive compound diallyl trisulfide. Indian J Exp Biol. 2011; 49(11): 805-816.

45. Galeone C, Pelucchi C, Levi F, et al. Onion and garlic use and human cancer. Am J Clin Nutr. 2006; 84(5): 1027-1032. doi: 10.1093/ajcn/84.5.1027

46. Hsing AW, Chokkalingam AP, Gao YT, et al. Allium vegetables and risk of prostate cancer: A population-based study. J Natl Cancer Inst. 2002; 94(21): 1648-1651. doi: 10.1093/jnci/94.21.1648

47. Islam M, Kusumoto Y, Al-Mamun MA. Cytotoxicity and cancer (HeLa) cell killing efficacy of aqueous garlic (Allium sativum) extract. J Sci Res. 2011; 3(2): 375-382. doi: 10.3329/jsr.v3i2.6557

48. Wang HC, Pao J, Lin SY, Sheen LY. Molecular mechanisms of garlic-derived allyl sulfides in the inhibition of skin cancer progression. Ann N Y Acad Sci. 2012; 1271(1): 44-52. doi: 10.1111/j.1749-6632.2012.06743.x

49. Anthony JP, Fyfe L, Smith H. Plant active components-a resource for antiparasitic agents. Trends Parasitol. 2005; 21(10): 462468. doi: 10.1016/j.pt.2005.08.004

50. Ahmed M, Laing M, Nsahlai I. In vitro anthelmintic activity of crude extracts of selected medicinal plants against Haemonchus contortus from sheep. J Helminthol. 2013; 87(2): 174-179. doi: 10.1017/S0022149X1200020X

51. Lima CM, Freitas FI, Morais LC, Cavalcanti MG, Silva LF, Padilha RJ. Ultrastructural study on the morphological changes to male worms of Schistosoma mansoni after in vitro exposure to allicin. Rev Soc Bras Med Trop. 2011; 44: 327-330. doi: 10.1590/ s0037-86822011005000023

52. Iqbal Z, Nadeem QK, Khan M, Akhtar M, Waraich FN. In vitro anthelmintic activity of Allium sativum, Zingiber officinale, Curcurbita mexicana and Ficus religiosa. International Journal of Agriculture and Biology. 2001; 3(4): 454-457.

53. Dkhil M, Abdel-Baki A, Wunderlich F, Sies H, Al-Quraishy S. Anticoccidial and antiinflammatory activity of garlic in murine Eimeria papillata infections. Vet Parasitol. 2011; 175(1-2): 66-72. doi: 10.1016/j.vetpar.2010.09.009

54. Gallwitz H, Bonse S, Martinez-Cruz A, Schlichting I, Schumacher K, Krauth-Siegel RL. Ajoene is an inhibitor and subversive substrate of human glutathione reductase and Trypanosoma cruzi trypanothione reductase: Crystallographic, kinetic, and spectroscopic studies. J Med Chem. 1999; 42(3): 364-372. doi: $10.1021 /$ jm $980471 \mathrm{k}$

55. Klimpel S, Abdel-Ghaffar F, Al-Rasheid KA, et al. The effects of different plant extracts on nematodes. Parasitol Res. 2011; 
108(4): 1047-1054. doi: 10.1007/s00436-010-2168-4

56. Abdel-Ghaffar F, Semmler M, Al-Rasheid K, et al. The effects of different plant extracts on intestinal cestodes and on trematodes. Parasitol Res. 2011; 108: 979-984. doi: 10.1007/s00436-0102167-5

57. Kalu I, Ofoegbu U, Eroegbusi J, Nwachukwu C, Ibeh B. Larvicidal activities of ethanol extract of Allium sativum (garlic bulb) against the filarial vector, Culex quinquefasciatus. Journal of Medicinal Plants Research. 2010; 4(6): 496-498.

58. Martinez-Velazquez M, Rosario-Cruz R, Castillo-Herrera G, Flores-Fernandez J, Alvarez A, Lugo-Cervantes E. Acaricidal effect of essential oils from Lippia graveolens (Lamiales: Verbenaceae), Rosmarinus officinalis (Lamiales: Lamiaceae), and Allium sativum (Liliales: Liliaceae) against Rhipicephalus (Boophilus) microplus (Acari: Ixodidae). J Med Entomol. 2011; 48(4): 822-827. doi: $10.1603 / \mathrm{me} 10140$

59. Meriga B, Mopuri R, MuraliKrishna T. Insecticidal, antimicrobial and antioxidant activities of bulb extracts of Allium sativum. Asian Pac J Trop Med. 2012; 5(5): 391-395. doi: 10.1016/S19957645(12)60065-0

60. Tedeschi P, Leis M, Pezzi M, Civolani S, Maietti A, Brandolini V. Insecticidal activity and fungitoxicity of plant extracts and components of horseradish (Armoracia rusticana) and garlic (Allium sativum). J Environ Sci Health B. 2011; 46(6): 486-490. doi: 10.1080/03601234.2011.583868

61. Ban JO, Lee DH, Kim EJ, et al. Antiobesity effects of a sulfur compound thiacremonone mediated via down-regulation of serum triglyceride and glucose levels and lipid accumulation in the liver of db/db mice. Phytother Res. 2012; 26(9): 1265-1271. doi: $10.1002 /$ ptr.3729

62. Shih P-C, Kuo C-H, Juang J-Y, Liu C-H, Hsu L, Liu C-T. Effects of garlic oil on the migration of neutrophil-like cell studied by using a chemotactic gradient Labchip. Bio Med Res Int. 2010; 2010. doi: 10.1155/2010/319059

63. Hodge G, Hodge S, Han P. Allium sativum (garlic) suppresses leukocyte inflammatory cytokine production in vitro: Potential therapeutic use in the treatment of inflammatory bowel disease. Cytometry. 2002; 48(4): 209-215. doi: 10.1002/cyto.10133

64. Chiang Y-H, Jen L-N, Su H-Y, Lii C-K, Sheen L-Y, Liu C-T. Effects of garlic oil and two of its major organosulfur compounds, diallyl disulfide and diallyl trisulfide, on intestinal damage in rats injected with endotoxin. Toxicol Appl Pharmacol. 2006; 213(1): 46-54. doi: 10.1016/j.taap.2005.08.008

65. Lin GH, Lee YJ, Choi DY, et al. Anti-amyloidogenic effect of thiacremonone through anti-inflamation in vitro and in vivo models. J Alsheimers Dis. 2012; 29(3): 659-676. doi: 10.3233/JAD2012-111709
66. Banerjee S, Maulik M, Manchanda S, Dinda A, Das T, Maulik S. Garlic-induced alteration in rat liver and kidney morphology and associated changes in endogenous antioxidant status. Food Chem Toxicol. 2001; 39(8): 793-797. doi: 10.1016/s02786915(01)00018-7

67. Yin J, Li H. Anaphylaxis caused by younger garlic: Two cases report in China. Journal of Allergy and Clinical Immunology. 2007; 119(1): S34. doi: 10.1016/j.jaci.2006.11.151

68. Chan KC, Yin MC, Chao WJ. Effect of diallyl trisulfide-rich garlic oil on blood coagulation and plasma activity of anticoagulation factors in rats. Food Chem Toxicol. 2007; 45(3): 502-507. doi: $10.1016 /$ j.fct.2006.10.005

69. Coppo E, Marchese A. Antibacterial activity of polyphenols. Current Pharmaceutical Biotechnology. 2014; 15(4): 380-390. doi: 10.2 174/138920101504140825121142

70. Radulovic N, Blagojevic P, Stojanovic-Radic Z, Stojanovic N. Antimicrobial plant metabolites: Structural diversity and mechanism of action. Curr Med Chem. 2013; 20(7): 932-952.

71. Stefanović OD. Synergistic activity of antibiotics and bioactive plant extracts: A study against gram-positive and gram-negative bacteria. In: Bacterial Pathogenesis and Antibacterial Control. 2018: 23. doi: 10.5772/intechopen. 72026

72. Cai Y, Wang R, Pei F, Liang B. Antibacterial activity of allicin alone and in combination with $\beta$-lactams against Staphylococcus spp. and Pseudomonas aeruginosa. J Antibiot (Tokyo). 2007; 60: 335-338. doi: 10.1038/ja.2007.45

73. Palaksha MN, Ahmed M, Das S. Antibacterial activity of garlic extract on streptomycin-resistant Staphylococcus aureus and Escherichia coli solely and in synergism with streptomycin. J Nat Sci Biol Med. 2010; 1: 12-15. doi: 10.4103/0976-9668.71666

74. Ogita A, Nagao Y, Fujita K, Tanaka T. Amplification of vacuole-targeting fungicidal activity of antibacterial antibiotic polymyxin B by allicin, an allyl sulfur compound from garlic. J Antibiot. 2007; 60: 511-518. doi: 10.1038/ja.2007.65

75. Abubakar E-MM. Efficacy of crude extracts of garlic (Allium sativum Linn.) against nosocomial Escherichia coli, Staphylococcus aureus, Streptococcus pneumoniea and Pseudomonas aeruginosa. Journal of Medicinal Plants Research. 2009; 3(4): 179-185.

76. Berginc K, Žakelj S, Kristl A. In vitro interactions between aged garlic extract and drugs used for the treatment of cardiovascular and diabetic patients. Eur J Nutr. 2010; 49(6): 373-384. doi: $10.1007 / \mathrm{s} 00394-010-0095-\mathrm{x}$

77. Friedman T, Shalom A, Westreich M. Self-inflicted garlic burns: Our experience and literature review. Int J Dermatol. 2006; 45(10): 1161-1163. doi: 10.1111/j.1365-4632.2006.02860.x 
78. Tattelman E. Health effects of garlic. Am Fam Physician. 2005; 72: 103-106.

79. Hamlaoui-Gasmi S, Mokni M, Limam N, et al. Grape seed and skin extract mitigates garlic-induced oxidative stress in rat liver. Can J Physiol Pharmacol. 2012; 90(5): 547-556. doi: 10.5897/ JMPR11.1035 